\title{
Craniopharyngioma with hyperprolactinaemia due to a prolactinoma
}

\author{
T WHEATLEY, J D A CLARK, S STEWART* \\ From the Departments of Diabetes and Endocrinology, and of Pathology, ${ }^{*}$ Addenbrooke's Hospital, \\ Cambridge, UK
}

SUMMARY A case is presented in which a histologically proven prolactin secreting pituitary macroadenoma was associated with a large suprasellar craniopharyngioma. The pre-operative prolactin concentration was $8180 \mathrm{mU} / \mathrm{l}$. Although hyperprolactinaemia up to $3000 \mathrm{mU} / 1$ in patients with a craniopharyngioma is usually due to stalk compression, greater values may indicate an associated prolactinoma.

Craniopharyngioma may be associated with moderate hyperprolactinaemia, galactorrhoea and disturbance of the hypothalamo-pituitary-gonadal axis. ${ }^{1-4}$ However, in these cases as serum prolactin concentrations are usually less than $3000 \mathrm{mU} / 1$ $(150 \mathrm{ng} / \mathrm{ml})$ and histo-pathological studies do not show prolactin secreting adenomata, the elevated levels are probably due to stalk compression. ${ }^{5}$ We report the first case in which a large suprasellar craniopharyngioma was associated with a prolactin secreting pituitary adenoma.

\section{Case report}

A 61-year-old man presented with a 9 month history of gradually deteriorating vision and difficulty with lateral vision while driving. In addition, he had noted reduced libido for 10 years, intermittent headaches for 2 years and cold intolerance for 2 months. He shaved daily and had no other symptoms suggestive of endocrine dysfunction. Hypertension had been diagnosed 7 years previously and treated with oxprenolol. His previous health had otherwise been satisfactory. There was a family history of ischaemic heart disease but not of neurological or endocrinological problems.

Examination revealed a corrected visual acuity of $N / 2$ on the right and N/14 on the left, a bitemporal hemianopia, with a left lower quadrantic nasal field defect and bilateral pallor of the optic discs. He was moderately obese with nor-

Address for reprint requests: Dr T Wheatley, Clinic 12, Addenbrooke's Hospital, Hills Road, Cambridge CB2 2QQ, UK.

Received 31 December 1985 and in revised form 13 March 1986. Accepted 15 March 1986 mal secondary sexual characteristics and had no galactorrhoea or signs of hypothyroidism or hypoadrenalism. His right brachial blood pressure was $150 / 100 \mathrm{~mm} \mathrm{Hg}$ without postural fall and examination of remaining systems was normal.

Initial investigations showed an increased cardiac diameter of $16 \mathrm{~cm}$ without evidence of pulmonary oedema, a normal 12 lead ECG and normal plasma electrolytes, serum calcium, blood glucose and serum protein concentrations. Tests of endocrine function showed a serum prolactin concentration of $8180 \mathrm{mU} / \mathrm{l}$ (normal range for males <150) and a serum testosterone of $5.6 \mathrm{nmol} / 1$ (normal range for males 10-38). The results of other endocrine investigations were normal (table).

A plain skull radiograph was normal without evidence of pituitary fossa enlargement or abnormal calcification and a CT brain scan revealed a non-enhancing, low density area in the left suprasellar region, with a normal sella. Bilateral carotid angiography showed an avascular space-occupying lesion in the suprasellar region with elevation and posterior displacement of the anterior cerebral arteries. As the radiological findings were consistent with a craniopharyngioma and the results of endocrine function tests were unavailable at that stage the lesion was explored, under hydrocortisone cover, using a subfrontal approach via a coronal flap. This revealed a cystic craniopharyngioma, confirmed histologically, which was subtotally resected leaving a fragment of the capsule which was adherent to the optic nerve. No tumour was seen arising from the sella.

Following an uneventful post-operative recovery there was a progressive improvement in his visual fields, although investigation 6 weeks later showed that the serum prolactin remained elevated at $5650 \mathrm{mU} / 1$ (table).

However, 2 months after operation his visual acuity deteriorated from N2 on the right and N14 on the left, to N14 on the right and N18 on the left and he became 
Table Endocrine results

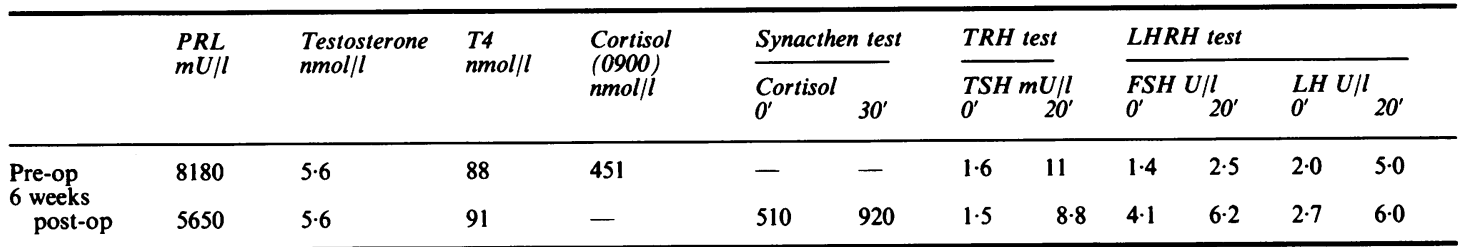

Normal values: PRL < $150 \mathrm{mU} / 1$. Testosterone $10-38 \mathrm{nmol} / 1$ (males). T4 65-145 nmol/1. Cortisol (0900) 280-650 nmol/1.

Synacthen test-cortisol increment $>200 \mathrm{nmol} / \mathrm{l}$ and $30^{\prime}$ level $>500 \mathrm{nmol} / 1$.

TRH test-basal TSH 0-4 mU/l, peak TSH 6-22 mU/1.

LHRH test-peak FSH 1.5-10.5 U/1, peak LH 7-27 U/1.

increasingly confused with memory impairment and somnolence. A CT brain scan showed an enhancing mass occupying the pituitary fossa and extending upwards to the level of the foramen of Monro, obliterating the suprasellar cisterns and 3rd ventricle with posterior displacement of the frontal horns of the lateral ventricles. Extensive regrowth of the residual multicystic craniopharyngioma was thought to have been responsible for the increase in tumour size in this CT scan. Under general anaesthesia, with hydrocortisone cover, a stereotactic biopsy was taken and a ventriculo-atrial shunt inserted but he suffered a fatal post-operative cardiac arrest.

\section{Pathological findings}

The cause oi death at necropsy was acute heart failure due to severe pre-existing hypertensive heart disease. The base of the brain showed a friable nodule 1.5 by 1.0 by $0.5 \mathrm{~cm}$ in the pituitary fossa and tumour adherent to the left optic nerve and left internal carotid artery. The brain was sliced sagittally to maintain continuity between the third ventricle,

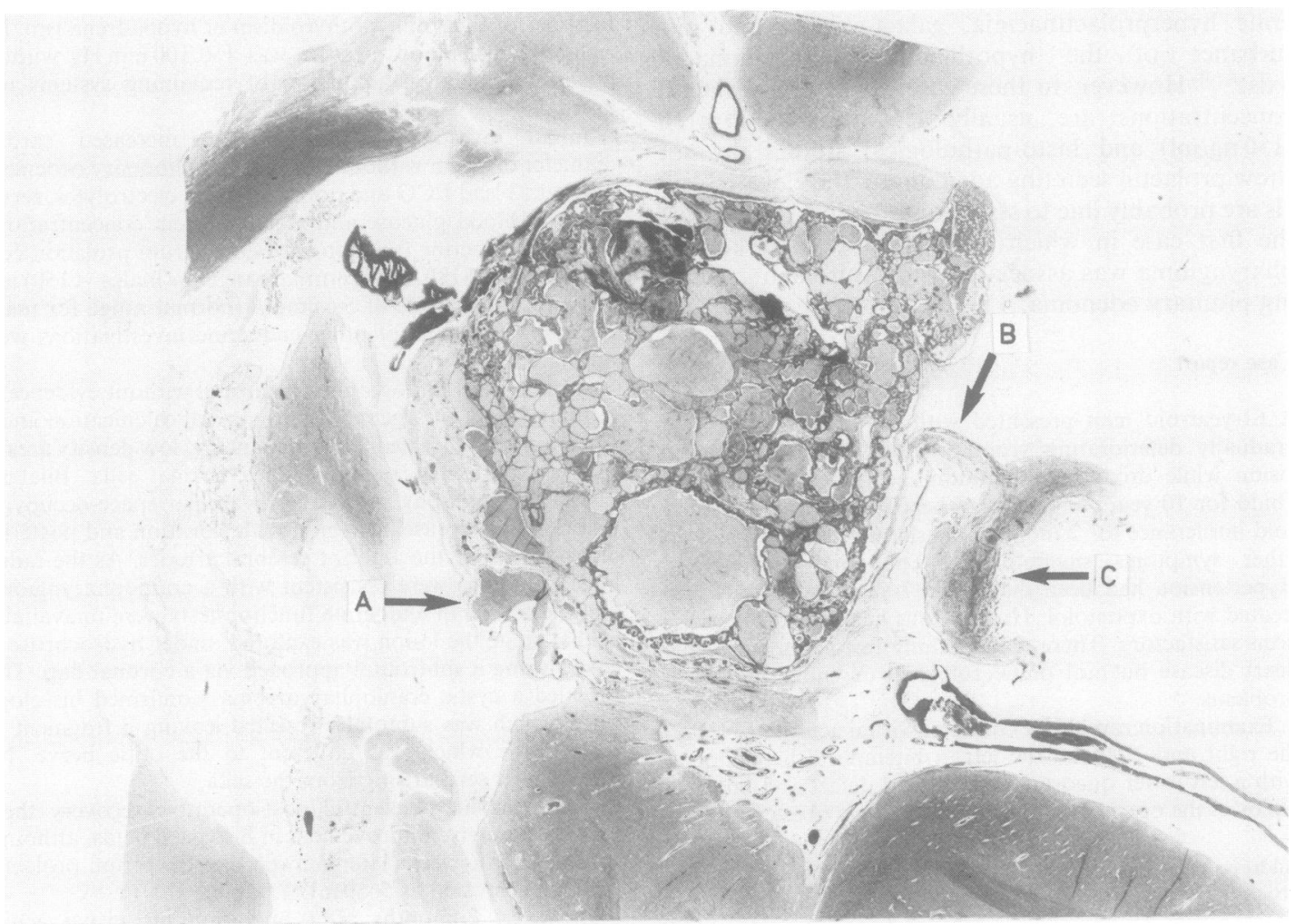

Fig 1 Low power view of multicystic suprasellar craniopharyngioma (A), pituitary stalk (B) and pituitary gland with tumour (C), parts of which have been removed for separate embedding. (Haematoxylin and eosin $\times 2$.) 


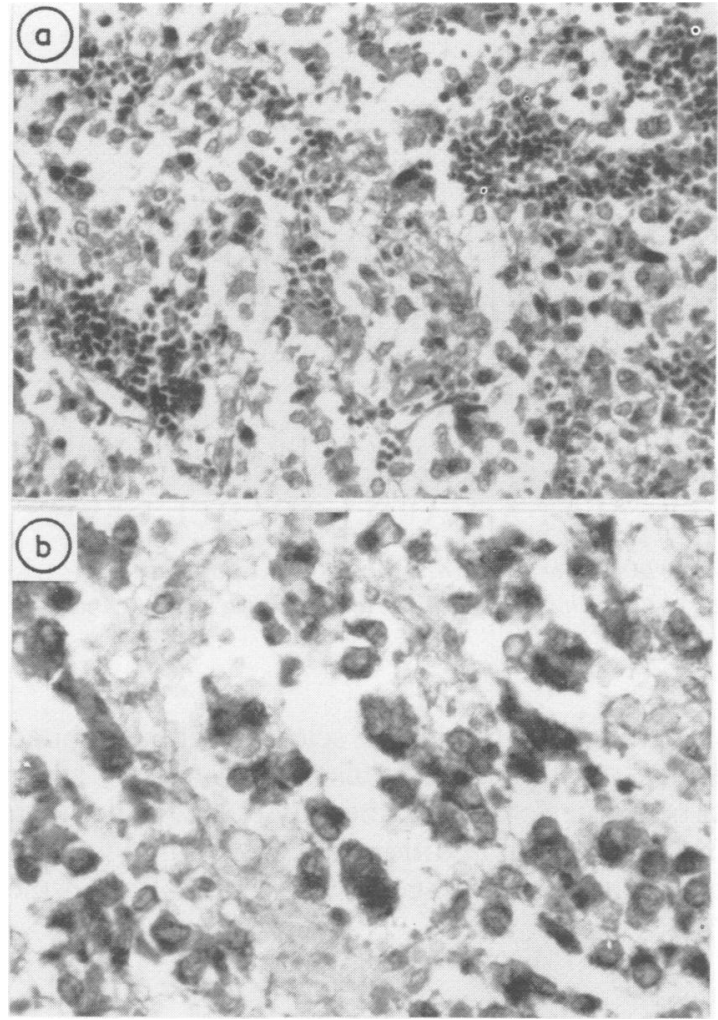

Fig 2 (a) Typical appearance of the pituitary adenoma showing sinusoidal arrangement of rather uniform cells with round to oval nuclei. (Haematoxylin and eosin $\times 200$.) (b) Pituitary adenoma stained for prolactin with cytoplasmic positivity in most of the cells. (Immunoperoxidase $\times 800$.)

hypothalamus, pituitary stalk and gland. The cut surface revealed a large, pale multicystic tumour mass up to $2.5 \mathrm{~cm}$ diameter in the suprasellar region, compressing the third ventricle and adherent to the optic nerve and carotid artery. The pituitary stalk appeared normal and the gland was compressed around a soft intrasellar tumour, part of which was removed for separate embedding (fig 1).

Histological sections showed the suprasellar tumour to be residual craniopharyngioma with typical anastomosing islands of basaloid cells around stellate reticulum. Squamous metaplasia, keratinisation, calcification and cystic degeneration were present. The craniopharyngioma extended around the left optic nerve and carotid artery but did not involve the pituitary stalk. There was a compressed rim of pituitary gland around an adenoma which, despite autolysis, showed rather uniform chromophobe cells arranged in a sinusoidal pattern (fig 2a). Immunocytochemical staining for prolactin using the peroxidaseantiperoxidase method on formalin-fixed paraffin embedded tissue was performed with the usual positive and negative controls to confirm specificity-Intense granular cytoplasmic positivity was seen in most of the cells of the adenoma (fig $2 \mathrm{~b}$ ). Scattered positive cells were noted in the rim of nor- mal pituitary. The craniopharyngioma was totally negative for prolactin.

\section{Discussion}

Two previous reports have described the association of a histologically proven Rathke's pouch cyst, hyperprolactinaemia and a pituitary tumour with positive immunoperoxidase staining for prolactin. In the first case amenorrhoea, a serum prolactin concentration of $4580 \mathrm{mU} / 1$ and pituitary fossa enlargement were due to a large Rathke's pouch cyst within the fossa and a prolactin secreting tumour. ${ }^{6}$ In the second amenorrhoea, a serum prolactin concentration of $1600 \mathrm{mU} / \mathrm{l}$ and a radiologically normal pituitary fossa were due to a "transitional cell tumour" of the pituitary gland which was noted to have features of both a Rathke's pouch cyst and a pituitary adenoma. ${ }^{7}$ However, the association reported here of a large suprasellar craniopharyngioma, marked hyperprolactinaemia and a histologically proven prolactin secreting pituitary macroadenoma has not been previously described. Thus, although hyperprolactinaemia of less than $3000 \mathrm{mU} / 1$, with or without disturbance of the hypothalamo-pituitary-gonadal axis, is frequently seen in patients with suprasellar tumours and is not associated with a prolactin secreting tumour, the coincidence of a prolactinoma should be considered when there is more marked elevation of the serum prolactin concentration.

We thank Dr OM Edwards and Mr AE Holmes for allowing us to report their patient. We are also indebted to Dr TD Hawkins for his expert neuroradiological advice.

\section{References}

${ }^{1}$ Jenkins JS, Gilbert CJ, Ang V. Hypothalamopituitary function in patients with craniopharyngiomas. $J$ Clin Endocrinol Metab 1976;43:394-9.

${ }^{2}$ Kapcala LP, Molitch ME, Post KD, et al. Galactorrhea, oligo/amenorrhea and hyperprolactinaemia in patients with craniopharyngiomas. J Clin Endocrinol Metab 1980;51:798-800.

${ }^{3}$ Lundberg PO, Osterman PO, Wide L. Serum prolactin in patients with hypothalamus and pituitary disorders. J Neurosurg 1981;55:194-9.

${ }^{4}$ Brandeis V, Kemmann E, Jones JR. Hyperprolactinemic amenorrhea in a woman with craniopharyngioma: persisting amenorrhea after prolactin suppression with bromocriptine. Am J Obstet Gynecol 1983;147:109-11.

${ }^{5}$ Arem R, Zoghbi W, Chan L. Amenorrhea-galactorrhea and craniopharyngioma. Surg Neurol 1983;20:109-12.

${ }^{6}$ Trokoudes KM, Walfish PG, Holgate RC, Pritzker KPH, Schwartz ML, Kovacs K. Sellar enlargement with hyperprolactinaemia and a Rathke's pouch cyst. JAMA 1978;240:471-3.

${ }^{7}$ Pearl GS, Takei Y, Kurisaka M, Seyama S, Tindall GT. Cystic prolactinoma. Am J Surg Pathol 1981;5:85-90. 